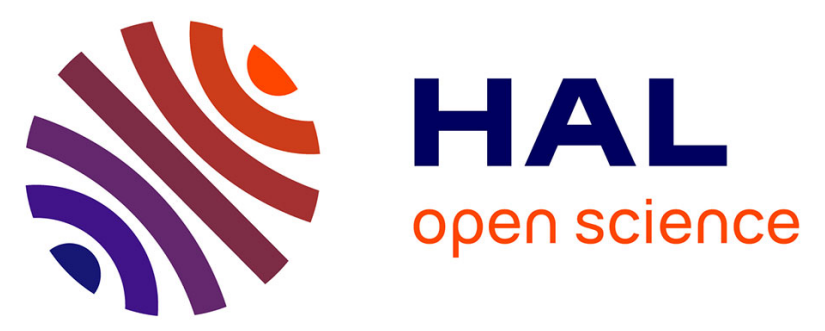

\title{
Extracellular vesicles from human cardiovascular progenitors trigger a reparative immune response in infarcted hearts
}

Bruna Lima Correa, Nadia El Harane, Ingrid Gomez, Hocine Rachid Hocine, José Vilar, Manon Desgres, Valérie Bellamy, Kamaleswaran Keirththana, Chloé Guillas, Maria Perotto, et al.

\section{To cite this version:}

Bruna Lima Correa, Nadia El Harane, Ingrid Gomez, Hocine Rachid Hocine, José Vilar, et al.. Extracellular vesicles from human cardiovascular progenitors trigger a reparative immune response in infarcted hearts. Cardiovascular Research, 2020, pp.cvaa028. 10.1093/cvr/cvaa028 . inserm-02563336

\section{HAL Id: inserm-02563336 https://www.hal.inserm.fr/inserm-02563336}

Submitted on 5 May 2020

HAL is a multi-disciplinary open access archive for the deposit and dissemination of scientific research documents, whether they are published or not. The documents may come from teaching and research institutions in France or abroad, or from public or private research centers.
L'archive ouverte pluridisciplinaire HAL, est destinée au dépôt et à la diffusion de documents scientifiques de niveau recherche, publiés ou non, émanant des établissements d'enseignement et de recherche français ou étrangers, des laboratoires publics ou privés. 


\title{
Extracellular vesicles from human cardiovascular progenitors trigger a reparative immune response in infarcted hearts
}

\author{
Lima Correa et al.
}

Extracellular vesicles and cardiac inflammatory reaction

Bruna Lima Correa 1†, Nadia El Harane1†, Ingrid Gomez1, Hocine Rachid Hocine2, José Vilar1,Manon Desgres1, Valérie Bellamy1, Keirththana Kamaleswaran 1, Chloé Guillas1, Maria Perotto1, Laetitia Pidial1, Paul Alayrac1, Thi Tran1, Sisareuth Tan3, Thomas Hamada1, Dominique Charron5, Alain Brisson3, Nisa K. Renault4, Reem Al-Daccak5, Philippe Menasché $1,6^{*}$, and Jean-Sébastien Silvestre1*

\author{
1. INSERM UMRS 970, Paris Centre de Recherche Cardiovasculaire (PARCC), Université de Paris, 56, rue \\ Leblanc, F-75015 Paris, \\ France; \\ 2. Institut Curie, F-75005 Paris, France; \\ 3. UMR-CBMN, CNRS-Université de Bordeaux-IPB, F-33600 Pessac, France; \\ 4. Fujifilm Cellular Dynamics Inc, Madison, WI 53711, USA; \\ 5. INSERM, UMRS-976, Hôpital Saint-Louis, F-75015 Paris, France; and \\ 6. Department of Cardiovascular Surgery, Hôpital Européen Georges Pompidou, 20, rue Leblanc, F-75015 Paris, \\ France \\ *.Corresponding authors. \\ Tel: +33(0)1 560936 22; fax: +33(0)1 560932 61, E-mail:philippe.menasche@aphp.fr(P.M.); \\ Tel: +33 (0)1 539880 60; fax: +33(0) 15398 79 51, E-mail: jeansebastien.silvestre@inserm.fr (J.-S.S.) \\ †. The first two authors contributed equally to the study and are co-first authors
}

\section{Abstract}

The cardioprotective effects of human induced pluripotent stem cell-derived cardiovascular progenitor cells (CPC) are largely mediated by the paracrine release of extracellular vesicles (EV). We aimed to assess the immunological behaviour of EV-CPC, which is a prerequisite for their clinical translation. Flow cytometry demonstrated that EV-CPC expressed very low levels of immune relevant molecules including HLA Class I, CD80, CD274 (PD-L1), and CD275 (ICOS-L); and moderate levels of ligands of the natural killer (NK) cell activating receptor, NKG2D. In mixed lymphocyte reactions, EV-CPC neither induced nor modulated adaptive allogeneic $\mathrm{T}$ cell immune responses. They also failed to induce NK cell degranulation, even at high concentrations. These in vitro effects were confirmed in vivo as repeated injections of EV-CPC did not stimulate production of immunoglobulins or affect the interferon (IFN)- $\gamma$ responses from primed splenocytes. In a mouse model of chronic heart failure, intra-myocardial injections of EV-CPC, 3 weeks after myocardial infarction, decreased both the number of cardiac pro-inflammatory Ly6Chigh monocytes and circulating levels of pro-inflammatory cytokines (IL- $1 \alpha$, TNF- $\alpha$, and IFN- $\gamma$ ). In 
a model of acute infarction, direct cardiac injection of EV-CPC 2 days after infarction reduced pro-

inflammatory macrophages, Ly6Chigh monocytes, and neutrophils in heart tissue as compared to controls. EV-CPC also reduced levels of pro-inflammatory cytokines IL-1 $\alpha$, IL-2, and IL-6, and increased levels of the anti-inflammatory cytokine IL-10. These effects on human macrophages and monocytes were reproduced in vitro; EV-CPC reduced the number of pro-inflammatory monocytes and M1 macrophages, while increasing the number of anti-inflammatory M2 macrophages.

EV-CPC do not trigger an immune response either in in vitro human allogeneic models or in immunocompetent animal models. The capacity for orienting the response of monocyte/macrophages towards resolution of inflammation strengthens the clinical attractiveness of EV-CPC as an acellular therapy for cardiac repair.

Keywords: Acellular therapies, Heart Failure, Extracellular vesicles, Immunomodulatory effects 


\section{Introduction}

Despite therapeutic improvements, chronic heart failure still carries a poor prognosis with a 5-year mortality averaging 50\% ${ }^{1}$. When drug-based regimens are no longer effective, heart transplantation or mechanical assist devices may be indicated, but their invasiveness and limitations call for alternate options, include cell therapy. Even though, so far, cell therapy trials have largely failed to significantly improve patient outcomes, they have provided some insights into the mechanism of action of transplanted cells which appears to be predominantly mediated by paracrine signaling ${ }^{2}$. This concept is largely based on the observations that the secretome, including extracellular vesicles (EV), is as effective as the parent therapeutic cells in the treatment of experimental cardiomyopathies ${ }^{3,4}$. We have previously shown, in a mouse model of chronic heart failure, that EV released by embryonic stem cell derived cardiovascular progenitor cells (CPC) ${ }^{5}$ and EV released by induced pluripotent stem cells (iPSC) derived CPC ${ }^{6}$ were therapeutically effective. Others have shown this to be the case for the secretome of other cell types, primarily mesenchymal stem cells ${ }^{7,8}$ and cardiac stem cells ${ }^{9,10}$.

Extracellular vesicles are membrane-bound particles ranging in size from less than $100 \mathrm{~nm}$ to $1 \mu \mathrm{m}$ and found in all biological fluids and conditioned media ${ }^{11}$. They are composed of a bi-lipid membrane, similar to the cell membrane, which encloses an aqueous, nucleus-free compartment, harboring mRNAs, microRNAs, proteins, lipids, and other bioactive molecules ${ }^{12-16}$. Although a consensus has not yet been reached on specific markers of EV subtypes, EV can be characterized by the expression of proteins like the tetraspanins (CD9, CD63 and CD81) and integrins while additional features of their profile depend on the phenotype of the parent cell ${ }^{17-20}$. Furthermore, while the molecular mechanisms underpinning the cardio-protective effects of EV are still under investigation, the therapeutic potential of EV likely relies on pleiotropic effects including angiogenesis, modulation of the inflammatory environment and, possibly, activation of cardiac intrinsic regenerative pathways ${ }^{5,6,21-24}$.

Yet, to the best of our knowledge, most of the studies investigating the cardio-reparative effects of human EV have been conducted in immune-deficient experimental animal models. Although these studies provide valuable mechanistic insights, a more clinically relevant assessment of the immune 
effects of EV, which is a prerequisite for their potential clinical use, requires their exposure to human cells and the use of immune-competent animal models. In the present study, we used tailored allogeneic in vitro human cell assays and immunocompetent mouse models of myocardial infarction (MI) to investigate the immune effects of EV derived from human CPC. 


\section{Material and Methods}

Detailed Material and Methods are given in the Supplemental Material.

\section{Ethics section}

All procedures were approved by the Institutional Ethics Committee from the Université de ParisDescartes (project \#04073.01) and comply with European legislation (European Commission Directive 2010/63/EU) on animal care. All animals received humane care in compliance with the "Principles of Laboratory Animal Care" formulated by the National Society for Medical Research and the "Guide for the Care and Use of Laboratory Animals" prepared by the Institute of Laboratory Animal Resources and published by the National Institutes of Health (NIH guidelines). All animals received anesthesia by isoflurane $\left(2.5 \mathrm{~L} / \mathrm{min}\right.$ isoflurane at $1.5 \mathrm{~L} / \mathrm{min}$ of $\mathrm{O}_{2}$ ) and were euthanized by dolethal injection at $140 \mathrm{mg} / \mathrm{kg}$. For in vitro tests with human cells, blood donors signed an informed consent and all methods and experimental protocols were approved by the institutional Ethics Committee (Hôpital St. Louis, Paris, France) and conducted in accordance with guidelines and regulation outlined in the Declaration of Helsinki.

\section{Cell culture, EV preparation, quantification and characterization}

\section{a) Cell Culture and cell characterization}

Cardiovascular progenitor cells differentiated from human iPSC (iCell® Cardiac Progenitor Cells, Cellular Dynamics International, Madison, WI) were cultured according to the manufacturer's directions (for a detailed protocol, see Supplementary Material). After 4 days of culture, cells were harvested and immune-phenotyped with antibodies against relevant immune molecules using fluorescence-activated cell sorting (FACS) (CANTO-II Flow Cytometer, BD Bioscience, DIVA and FlowJo software).

For human cell in vitro experiments, human peripheral blood mononuclear cells (PBMC) were prepared from blood samples from healthy donors using Ficoll gradient (Eurobio) centrifugation and cryopreserved for later use.

\section{b) $\mathbf{E V}$ isolation}


Conditioned media were collected, pre-cleared by centrifugation for 6 minutes at 1,200g and EV were pelleted by ultracentrifugation (rotor 70Ti-Beckman) for 16 hours at 100,000g.

\section{c) EV quantification and characterization}

Extracellular vesicles were quantified by Nanoparticle Tracking Analysis (NanoSight LM-14, Malvern) and characterized by FACS ${ }^{25}$ after coupling with latex beads (Life Technologies, A37304) using a MACSplex kit (MACSPlex Exosome Kit human, Miltenyi Biotech) as follows to phenotype their membrane ligands.

In a second time, EV ( $25 \mu \mathrm{g}$ of protein) were mixed with 4- $\mu \mathrm{m}$ Aldehyde/Sulfate Latex Beads at room temperature (RT); then suspended in Phosphate-Buffered Saline (PBS) and left at RT for another $2 \mathrm{~h}$. The coupling reaction was terminated by $100 \mathrm{mM}$ glycine, and the mixture was centrifuged at 1,500 $\mathrm{x}$ g. The beads were then stained with conjugated antibodies for the relevant markers and analyzed by FACS.

Ultimately immuno-gold labeling and cryo-transmission electron microscopy (cryo-TEM) were also performed on EV. Gold nanoparticles (NP) were conjugated with an anti-CD81 monoclonal antibody $(\mathrm{mAb})$ following procedures previously described ${ }^{26}$. Samples of EV were used either pure or diluted 10-fold with a HEPES ((4-(2-hydroxyethyl)-1-piperazineethanesulfonic acid)buffered saline containing $150 \mathrm{mM} \mathrm{NaCl}$ and $10 \mathrm{mM}$ HEPES, pH 7.4. Samples were then labeled for $1 \mathrm{~h}$ with 10-nm anti-CD81-gold-NP at 1-3 $\times 10^{15}$ gold-NP/L, at RT. Immuno-gold labeled samples were processed for cryo-TEM as follows. A $4-\mu \mathrm{L}$ aliquot was deposited on an electron microscopy (EM) grid coated with a perforated carbon film. After draining the excess liquid with a filter paper, grids were quickly plunged into liquid ethane using a Leica EMCPC cryo-chamber, transferred to cryo-boxes and stored under liquid nitrogen until TEM observation. For cryo-TEM observation, grids were mounted onto a Gatan 626 cryoholder and transferred to a Tecnai F20 microscope (FEI) operated at $200 \mathrm{kV}$. Images were recorded with a USC1000-SSCCD camera (Gatan). These experiments were performed to best match the minimal Information for Studies of Extracellular Vesicles ("MISEV") guidelines ${ }^{27}$.

On the basis of a previous study ${ }^{6}$ in which the cardioprotective effects of $1.4 \times 10^{6} \mathrm{CPC}$ could be recapitulated by delivering the amount of EV they had secreted in 48 hours, we selected in the present study the same EV dose which equates here to $1 \times 10^{10}$ particles $(100 \mu \mathrm{g}$ of protein) concentrated in a $50-60 \mu \mathrm{L}$-volume. 


\section{Allogeneic immune responses and immunomodulation assays}

Tailored mixed lymphocyte reactions (MLR) were performed using PBMC from different donors. Briefly, responding PBMC $\left(1 \times 10^{5}\right.$ cells $)$ were labeled with $2.5 \mu \mathrm{M}$ carboxyfluorescein succinimidyl ester (CFSE, Thermofisher Scientific) and then co-cultured in Roswell Park Memorial Institute (RPMI) medium supplemented with 10\% Fetal Bovine Serum (FBS, Gibco Life Technologies) in U-bottom 96-well plates (VWR) with human leukocyte antigen mismatched (HLA) mitomycin-C-treated (Sigma) stimulatory PBMC ( $1 \times 10^{5}$ cells), mitomycin-C-treated CPC

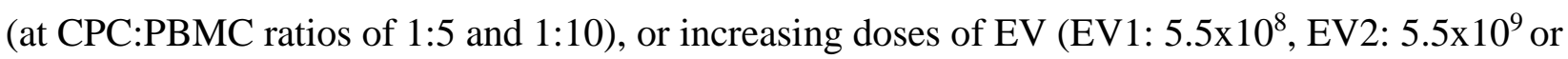
EV3: $1.7 \times 10^{10}$ particles) or PBS as a control. After 6 days of co-culture, cells were harvested and stained with anti-CD3-PE/Cy7, anti-CD4-APC, anti-CD8-APC-H7 antibodies and 7AAD (BD Biosciences). Proliferation and cell death of T-cell subsets were monitored by FACS.

In assays determining the immunomodulatory effects of CPC and EV-CPC, HLA-mismatched CFSE-labeled PBMC ( $1 \times 10^{5}$ cells) were stimulated with $1 \mu \mathrm{g} / \mathrm{mL}$ phytohemagglutinin (SigmaAldrich) in the presence or absence of mitomycin-C-treated CPC (at CPC: PBMC ratios of 1:5 and 1:10) or with increasing concentrations of EV (EV1: $5.5 \times 10^{8}$, EV2:5.5 $\times 10^{9}$ or EV3: $1.7 \times 10^{10}$ particles) for 5 days. At the end of the co-culture, the proliferation and death rate of the $\mathrm{T}$ cells were monitored by FACS.

\section{Natural killer cell degranulation}

Natural Killer (NK) cells were isolated from PBMC by negative selection using immune-magnetic cell sorting (Miltenyi Biotech, Germany) according to the manufacturer's instructions. Experiments were conducted with NK cells primed overnight with recombinant human interleukine (II), IL-15 (50 ng/mL) (Sigma) in RPMI medium supplemented with 10\% FBS to ensure their proper expression of NK cell activating receptors and functionality. Cytokine-activated NK cells were cultured alone or in the presence of K562 cells used as positive controls (ATCC, USA), CPC (ratio 1:1) or increasing doses of $\mathrm{EV}\left(5.5 \times 10^{8} ; 5.5 \times 10^{9}\right.$ or $1.7 \times 10^{10}$ particles) and labelled with an anti-CD107a-PE antibody (BD Bioscience). After 18 hours, cells were harvested, washed and stained with CD3-APC-H75R (BD Bioscience) and CD56-APC specific antibodies (BD Bioscience), and the expression of CD107a was analyzed on CD3 ${ }^{-} \mathrm{CD}^{-} 6^{+} \mathrm{NK}$ cells by FACS. 


\section{Macrophage polarization assay}

PBMC from healthy donors were suspended at a concentration of 100 million cells per $\mathrm{mL}$ in Monocyte Attachment Medium (Promocell) and seeded at a density of 1 million viable cells/cm ${ }^{2}$ with a monocyte content $\geq 25 \%$ and 1.5 million viable cells $/ \mathrm{cm}^{2}$ for a monocyte content of $<25 \%$ (4 million cells per P24-well). At day 0, monocytes were incubated for 90 min at $5 \% \mathrm{CO}_{2}$ and $37^{\circ} \mathrm{C}$ to allow adherence. Non-adherent cells were discarded by vigorously swirling the culture and aspirating the supernatant. Adherent cells were then washed and the appropriate amount of complete M0, M1, M2 Macrophage Generation Medium (Promocell) was added to the cells for 6 days. Under these conditions, monocytes differentiate into M1-like or M2-like polarized macrophages. After 6 days, the culture medium was replaced with fresh complete M0, M1, M2 Macrophage Generation Medium DXF with or without EV (5.5x10 ${ }^{9}$ particles per well). Macrophages were then incubated for another 2 days at $37^{\circ} \mathrm{C}$ and $5 \% \mathrm{CO}_{2}$. At day 8 , the culture medium was supplemented with IFN- $\gamma(50 \mathrm{ng} / \mathrm{mL})$ and LPS (10 ng/mL) for M1 macrophage polarization, with $20 \mathrm{ng} / \mathrm{mL}$ IL-4 and 20ng/mL IL-13 for M2 macrophage polarization (all from Merck) or with macrophage colony-stimulating factor (MCSF) medium for M0 macrophages. Each of these conditions was exposed or not to EV (5.5x $10^{9}$ particles per well). The next day (D9), cells were detached with the Macrophage Detachment Solution DXF (Promocell) for 45 min at RT. Monocytes and macrophages were analyzed at day 9 of culture, after polarization and exposure to $\mathrm{EV}$, as described above. They were suspended in MACSBuffer (Milteny), centrifuged for $10 \mathrm{~min}$ at $500 \mathrm{x}$ g, counted and labelled at 200,000 cells per condition with anti-CD64 PE, anti-CD68 PECy7, anti-CD80 PE-Cy5, anti-CD86 APC or BV605, anti-CD163 BV421, anti-CD206 BV711 and anti-CD14 FITC ((Fluorescein isothiocyanate) antibodies (all from BD Biosciences). Monocytes and macrophages were categorized by the following markers: Monocytes:CD14+; Proinflammatory monocytes: CD14+, CD86++; Macrophages: CD64+, CD68+; M1: CD64+, CD68+, CD80+, CD86+; M2a: CD64+, CD68+, CD206+; M2b: CD64+, CD 68+, CD163+. All antibodies were used at a dilution of 1:100. After incubation, cells were washed and suspended in $100 \mu \mathrm{L}$ of MACS Buffer for FACS analysis. Events were acquired on a Fortessa X20 flow cytometer (BD Biosciences); results were analyzed with FlowJo software (FlowJo V10.4.2, FlowJo LLC) and are given as a percentage of the whole population. Experiments were performed in technical triplicates for each donor. 


\section{Bead-based multiplex immunoassay}

A bead-based multiplex immunoassay (Bio-Rad) was used to measure the levels of multiple cytokines [basic Fibroblast Growth Factor, Eotaxin, G-CSF, GM-CSF, IFN- $\gamma$, IL-1 $\beta$, IL-1ra, IL-2, IL-4，IL-5，IL-6，IL-7，IL-8，IL-9，IL-10，IL-12 (p70), IL-13，IL-15，IL-17A，IP-10，MCP-1 (MCAF), MIP-1 $\alpha$, MIP-1 $\beta$, PDGF-BB, RANTES, Tumor Necrosis factor-alpha (TNF- $\alpha$ ), and VEGF] from supernatants of macrophage cultures at day 9. Concentration were calculated using a standard curve (5 PL regression, with Bio-Plex Manager ${ }^{\mathrm{TM}}$ software).

\section{Immunoglobulin assay following EV treatment}

To assess whether EV-CPC could induce antibody production, mice were subcutaneously injected at day 1,13 and 20 with either $\mathrm{EV}\left(\mathrm{n}=5\right.$, at the dose of $1 \times 10^{10}$ particles per injection) or PBS $(\mathrm{n}=5)$ according to a classical immunization protocol ${ }^{28}$. Blood samples were collected at days 10, 20 and 30 post injection. Ig isotypes in plasma were qualitatively detected using the mouse immunoglobulin isotyping ELISA kit (ThermoFisher Scientific).

\section{Enzyme-linked immunospot}

The enzyme-linked immunospot (ELISPOT) is a sensitive technique for the detection of cytokineproducing cells at the single cell level. The IFN- $\gamma$ ELISPOT (Diacole) method was used for measuring the antigen-specific response to EV-CPC elicited by NK cells, T cells, antigen-specific Th1 $\mathrm{CD}^{+}$and $\mathrm{CD}^{+}$effector T cells. Primed splenocytes of each vaccinated mouse were isolated, plated (at a seeding density of 1.5 million cells $/ \mathrm{cm}^{2}$ in 96 -well plates), and re-exposed to either EV ( $2 \times 10^{9}$ particles) or PBS in vitro for $21 \mathrm{~h}$; the positive control was a mixed solution of phorbol 12myristate 13-acetate (PMA, 100ng/mL) and ionomycine $(2 \mathrm{ug} / \mathrm{mL}$; both from Sigma) that triggers unspecific IFN- $\gamma$ production. When spots indicating IFN- $\gamma$ production appeared, they were counted using a Cellular Technology Ltd system (USA) and analyzed using ImmunoSpot 5.0.3 software. Results are reported as the mean of triplicate measurements of the number of IFN- $\gamma$ spot-forming cells (SFCs) per $5 \times 10^{5}$ plated cells.

\section{Mouse model of myocardial infarction (MI) and administration of EV-CPC}

Myocardial infarction was induced in C57BL/6JRj male mice (Janvier Laboratories) by permanent ligation of the left anterior descending coronary artery (LAD). In a first series of chronic heart 
failure, mice received 3 echo-guided, trans-cutaneous injections of 10-20 $\mu \mathrm{L}$ each, in peri-infarcted myocardium, 3 weeks after MI. The experimental groups were as follows: PBS, CPC (1.4 million cells), EV-CPC (secreted by 1.4 million CPC in 48 hours, which was $1 \times 10^{10}$ particles or $100 \mathrm{ug}$ of protein) or lipopolysaccharide (LPS dose of $22.5 \mu \mathrm{g}$, used as a positive control of inflammation). Six additional mice were also infarcted but did not receive any injection (controls). Except for the LPS injection group, which had a 33\% post-treatment mortality rate, all treated animals survived and were sacrificed 3 days after injection.

In an additional series of acute myocardial infarction, mice received similar transcutaneous echoguided injections in 3 peri-infarcted areas of either PBS (vehicle control) or EV-CPC (secreted by $1.4 \times 10^{6}$ CPC which was $1 \times 10^{10}$ particles or $100 \mu$ g of proteins) 2 days after the infarct. Efforts were made to reproducibly control the degree of cardiac injury in each series of experiments by carefully standardizing the coronary artery ligation site $2-3 \mathrm{~mm}$ below the atria all the samples respected this histomorphometric inclusion criteria.

\section{Tissue digestion and flow cytometry}

Tissues (heart, spleen, femur and blood) were collected 3 days after EV-CPC injections in both acute and chronic models and kept on ice during all procedures (except for blood). Hearts were rinsed in PBS to remove blood clots. The left ventricle was isolated, minced with fine scissors and gently passed through the Bel-Art ${ }^{\mathrm{TM}}$ Scienceware ${ }^{\mathrm{TM}}$ 12-Well Tissue Disaggregator (Bel-Art Products). Cells from heart, spleen and bone marrow were then collected in PBS, filtered through a 40- $\mu \mathrm{M}$ nylon mesh (Falcon) and washed. Red blood cells were removed by using the Red Blood Cell Lysing Buffer (Sigma). Cells harvested from the heart were immuno-stained at $4^{\circ} \mathrm{C}$ for 30 min. Total cardiac immune cells were gated after staining with an Alexa Fluor 700-conjugated antiCD45 antibody (BD Biosciences) and the following antibodies were used: $\mathrm{PE} / \mathrm{Cy} 7$-conjugated antiCD11b (BD Pharmingen), PA-conjugated anti-Ly6G (BD Pharmingen), BV421-conjugated antiCD64 (Biolegend), APC-conjugated anti-F4/80 (Bio-Rad), FITC-conjugated anti-Ly6C (BD Pharmingen), Percp5.5-conjugated MHC class II (Biolegend), FITC-conjugated anti-CD45R/B220 (eBioscience) and BV421-conjugated anti-CD3 (BD Pharmingen). All antibodies were used at a dilution of 1:100. After incubation, cells were washed and suspended in $100 \mu \mathrm{L}$ of PBS for FACS analysis. The total number of cells was normalized to heart weight. Events were acquired on an LSR II flow cytometer (BD Biosciences). Monocytes were categorized as Ly6C ${ }^{\text {high }}$ monocytes 
$\left(\mathrm{CD} 45+\mathrm{CD} 11 \mathrm{~b}^{+} \mathrm{F} 4 / 80^{-} \mathrm{Ly}^{-} 6 \mathrm{G}^{-}{ }^{-} 6 \mathrm{C}^{\text {high }}\right)$, and $\mathrm{Ly}^{\mathrm{low}}$ monocytes $\left(\mathrm{CD} 45+\mathrm{CD} 11 \mathrm{~b}^{+} \mathrm{F} 4 / 80^{-} \mathrm{Ly}^{-} \mathrm{G}^{-}\right.$ Ly6C $\left.{ }^{\text {low }}\right)$. Neutrophils were categorized as $\mathrm{CD} 45+\mathrm{CD} 11 \mathrm{~b}^{+} \mathrm{Ly}_{6 \mathrm{G}}{ }^{++} \mathrm{F} 4 / 80^{-} \mathrm{Ly} 6 \mathrm{C}^{\text {med }}$, and macrophages, as CD45+CD11 b ${ }^{+} \mathrm{Ly} 6 \mathrm{G}-\mathrm{F} 4 / 80^{+}{ }^{29}$.

\section{Bio-Plex ProTM}

The bead-based multiplex immunoassay (Bio-Rad) was used to measure the levels of pro- and antiinflammatory mediators from mouse plasma (chronic heart failure model) or cardiac tissue homogenates (chronic heart failure and acute myocardial infarction models), 3 days after EV-CPC injection. A 21-plex immunoassay panel (IL-1 $\alpha$ and $\beta$, IL-2, IL-3, IL-4, IL-5, IL-6, IL-9, IL-10, IL-12, IL-13, IL-17A, eotaxin, Granulocyte-colony stimulating factor (G-CSF), Granulocyte macrophage colony-stimulating factor (GM-CSF), IFN- $\gamma, \mathrm{KC}$, Monocyte chemoattractant protein (MCP-1 or CCL-2), MIP-1 $\alpha$, RANTES and TNF- $\alpha$ ) was used according to the manufacturer's directions and analysed on a Bio-Plex ${ }^{\circledR} 200$ (Bio-Rad). Analyte concentration was calculated using a standard curve (5 PL regression, with Bio-Plex Manager ${ }^{\mathrm{TM}}$ software).

\section{Statistical Analyses}

For all analyses, the Wilcoxon signed rank test was used and a $p$-value $<0.05$ was considered statistically significant, Mann-Whitney test was also used to compare two groups. Analyses were conducted using GraphPad InStat3 (8.0.1).

\section{Results}

EV-CPC and their parental cells display an immune phenotype compatible with allogeneic applications

The iPSC-derived CPC express SSEA-1/CD15, a marker of loss of pluripotency, in line with their cardiac progenitor identity. Immunologically, they express low levels of HLA-I and costimulatory/regulatory CD274 [PDL1], CD275[ICOS-1] and CD86 molecules, low levels of CD80 and of the ligands of the NK cell activating receptor NKG2D, ULBP-1, ULBP 2/5/6 and MIC-A/B and they did not express HLA-II (Figure 1a). The EV-CPC also express CD15 of their parent cells. Immunologically, they do not express HLA-I, HLA-II or costimulatory CD86 
molecules. They display low levels of CD80, PD-L1 and ICOS-1, and only modest levels of the ligands of NKG2D (Figure 1b).

To further characterize EV, we used the MACSplex kit to more extensively determine their surface marker profile. We detected CD9, CD29, CD49e, CD63, CD81 and CD326 (Epithelial Cell Adhesion Molecule-EPCAM), which are known to be abundantly expressed by EV, (Figure 1c and Supplemental Figure 1). The EV-CPC also expressed markers of an early differentiation stage including SSEA-4, CD133, CD105 and ROR1 and lacked the expression of markers not expected to be present on EV derived from CPC such as CD3, CD4 and CD14 (Supplemental Figure 1). The EV identity was further confirmed by the expression of CD81, as assessed by cryo-immuno gold electron microscopy (Figure 1d). EV consisted mostly of spherical vesicles ranging in size from 50 to $500 \mathrm{~nm}$ (Figure 1d-lower panel) and $40 \%$ of them were found to express the tetraspanin CD81.

\section{EV-CPC neither induce $T$ cell activation nor modulate their on-going proliferation}

The capacity of both CPC and their secreted EV to activate T cells in allogeneic settings was then evaluated. Co-culture of PBMC with allogeneic mitomycin-C-treated PBMC significantly activated both $\mathrm{CD}^{+}$and $\mathrm{CD}^{+}$cells, increasing the percentage of proliferating cells from $4 \%$ to $40 \%$. In contrast, neither $\mathrm{CD}^{+}$nor $\mathrm{CD}^{+}$cells responded to allogeneic mitomycin-c-treated $\mathrm{CPC}$ (Figure 2a). On the same note, PBMC cultured with EV-CPC maintained their basal proliferation rate and were not affected by EV (Figure 2a). The possibility of PBMC death by apoptosis as a potential cause of their non-proliferation was excluded by aminoactinomycine D7-AAD labeling (data not shown). Thus, neither CPC nor their secreted EV trigger any direct or indirect in vitro allogeneic T cell proliferation.

We then investigated the immunomodulatory capacity of EV-CPC in comparison to their parent cells. We evaluated PHA-induced $\mathrm{T}$ cell proliferation as an on-going $\mathrm{T}$ cell immune response model in the presence or absence of CPC or their secreted EV. The presence of CPC decreased both $\mathrm{PHA}$-induced $\mathrm{CD}^{+}$and $\mathrm{CD} 8^{+} \mathrm{T}$ cell proliferation by approximately $33 \%$, in a ratio-dependent manner (Figure $2 \mathrm{~b}$ ). In contrast, the presence of EV did not modulate PHA-induced CD4 ${ }^{+}$or $\mathrm{CD}^{+}$ $\mathrm{T}$ cell proliferation (Figure $2 \mathrm{~b}$ ), suggesting that they neither inhibit nor promote a $\mathrm{T}$ cell-mediated on-going immune response. 


\section{EV-CPC do not induce NK degranulation}

Similar to their parent cells, EV-CPC express ligands of the NKG2D receptor, albeit at a lower level. Therefore, we evaluated their capacity to trigger NK cell cytotoxicity in allogeneic settings by assessing their ability to induce degranulation of IL-15-primed NK cells. Compared to the classical NK cell target, (HLA-I-negative K562 cells), CPC modestly activated allogeneic NK cells. The percentage of NK cells specifically expressing the degranulation marker CD107a was approximately $26 \%$ in the presence of CPC compared to $45 \%$ in the presence of K562 cells. In contrast, the expression of CD107a on IL-15-primed NK cells was not affected by the presence of EV-CPC, even when a high dose of $1.7 \times 10^{10}$ particles was used (Figure 3). Thus, in line with their expression of ligands of NK cell activating receptors, only $\mathrm{CPC}$, but not their secreted $\mathrm{EV}$, are able to modestly activate NK cells.

\section{EV-CPC do not induce humoral nor cellular response in vivo}

To validate our in vitro findings, we then investigated the immune behavior of EV-CPC in an immunocompetent mouse model subjected to an immunization protocol. Mice were subcutaneously injected 3 times (at day 1, 10, 20) with either EV-CPC $(n=5)$ or PBS ( $n=5)$ and the humoral or cellular responses of injected mice against EV-CPC were determined. No statistically significant differences in immunoglobulin production were observed between controls and EVCPC-treated mice at any time point (Figure 4a). To evaluate the cellular immune response, splenocytes from treated and untreated mice were re-challenged in vitro with EV-CPC or PBS and the production of IFN- $\gamma$ was evaluated as a marker of effector T $\left(\mathrm{CD}^{+}\right.$and $\left.\mathrm{CD} 8^{+}\right)$and $\mathrm{NK}$ cell activation. Neither the splenocytes from EV-CPC-treated mice nor those from untreated mice produced detectable levels of IFN- $\gamma$ upon their re-exposure to EV-CPC (Figure $4 b$ ). Together, these data suggest that injecting immunocompetent recipients with EV-CPC is unlikely to trigger a pronounced humoral or cellular immune response.

\section{Immuno-inflammatory effects of EV-CPC in an immunocompetent mouse model of chronic heart failure}

We then investigated the immune response to EV-CPC in immunocompetent mice in which a MI had been created 3 weeks earlier. Inflammatory cells were harvested 3 days after treatment with PBS, CPC or EV-CPC. Lipopolysaccharide administration was used as a positive control to stimulate inflammation in the targeted cardiac tissue. As expected, the injection of LPS in the 
myocardium altered the profile of myeloid cell lines (Figure 5a), thereby confirming the capacity for these mice to mount an appropriate response to this endotoxin ${ }^{30}$. In infarcted hearts which were left untreated (controls), the overall number of inflammatory cells was low, consistent with a lower level of inflammation in chronic heart failure compared to acute MI ${ }^{31}$. Furthermore, PBS injection did not lead to significant changes in the immune profile of heart tissue when compared to untreated animals, thereby ruling out a significant immune response to the needle poke or introduction of fluid. Likewise, injection of EV-CPC or their parental cells did not induce any significant alteration in the numbers of adaptive cells (B and T), innate macrophages or neutrophils, as compared to controls. In contrast, they significantly decreased the number of inflammatory Ly6 $\mathrm{C}^{\text {high }}$ monocytes without any pronounced effect on Ly6C $\mathrm{C}^{\text {low }}$ monocytes.

EV-CPC and CPC injection did not affect the number of circulating (blood) adaptive immune cells, neutrophils or Ly6C $\mathrm{C}^{\text {low }}$ monocytes (Supplementary Figure 2a). However, as compared to controls, and in contrast to $\mathrm{EV}, \mathrm{CPC}$ injection reduced the number Ly6 $\mathrm{C}^{\text {high }}$ circulating monocytes. No significant difference between groups were observed in the immune profile of bone marrow (Supplemental Figure 3 a) or spleen cells (Supplemental Figure 3b), with the exception of a drastic drop of myeloid and lymphoid bone marrow cells in the LPS group ${ }^{32}$.

The expression profile of blood cytokine levels was in accordance. Infarcted mice treated with EVCPC or parental cells displayed decreased levels of the pro-inflammatory cytokines IL-1 $\alpha$, IL-1 $\beta$, $\mathrm{TNF} \alpha$, and IFN- $\gamma$ compared to the PBS control group (Figure 5b), while other cytokines were not affected (Supplemental Figure 2b).

Collectively, these data suggest that EV-CPC, similar to their parental cells, do not trigger any pronounced deleterious immune response in a chronic MI-induced left ventricle (LV) dysfunction model. They might rather downregulate pro-inflammatory compounds in cardiac tissue.

\section{Immuno-inflammatory effects of EV-CPC in an immunocompetent mouse model of acute myocardial infarction}

As the number of inflammatory cells in the infarcted heart was low 3 weeks post-infarct, the possibility was raised that the putative immunomodulatory potential of EV-CPC could have been missed due to the dampened inflammatory reaction at that stage of disease. Therefore, we assessed the immune-inflammatory effects of EV-CPC in an experimental model of acute MI which is 
associated with a large increase of immune/inflammatory cells in the cardiac tissue. In this model, mice were injected with EV-CPC or PBS 2 days after the infarct, and, as in the chronic model, cardiac inflammatory cells were harvested 3 days after treatment. Compared to control PBSinjected mice, EV-CPC treatment resulted in a significant decrease in neutrophils (from 140 to 50 cells per mg of tissue, $p=0.02$ ) and pro-inflammatory Ly6C $\mathrm{C}^{\text {high }}$ monocytes (from 160 to 70 cells per $\mathrm{mg}$ of tissue, $p=0.01$ ), but did not induce any significant differences in macrophages or adaptive $\mathrm{T}$ or B cell populations (Figure 6a). Cytokine profiling in cardiac tissue was in-line with these results, as EV-CPC induced a significant decrease in pro-inflammatory interleukins, IL-1 $\alpha$, IL-2, and IL6 , and a significant increase in the anti-inflammatory cytokine, IL-10. No noticeable differences were observed for other cytokines between the two groups (data not shown). EV-CPC treatment did not induce any significant alteration of tissue-resident cells in the bone marrow or the spleen (Supplemental Figure 4).

Collectively, our findings in the acute MI model support those observed in the chronic heart failure model and emphasize the capacity of EV-CPC to modulate immune/inflammatory responses towards a reparative profile.

\section{EV-CPC shape macrophage polarization state}

As our in vivo data had suggested that EV-CPC could act as modulators of monocyte/macrophage populations towards an anti-inflammatory phenotype, we assessed whether these effects were relevant to human cells. CD14+ monocytes were isolated from human PBMC and differentiated to M0-(M-CSF), M1-(LPS and IFN $\gamma$ ), or M2-macrophages (IL-4 and IL-13). Pro-inflammatory M1 macrophages were characterized as CD64+, CD68+, CD80+, CD86+ cells; and reparative macrophages as M2a (CD64+, CD68+, CD206+) or M2b (CD64+, CD68+, CD163+) (Supplementary Figure 5). Exposure of M0 to EV-CPC decreased the percentage of proinflammatory monocytes $\left(\mathrm{CD} 14^{+} \mathrm{CD}^{+}\right)$by 2.20 -fold (data not shown), and that of proinflammatory macrophages (CD64+ CD68+ CD86+ CD80+) by 2.26-fold. In this experimental setting, the percentage of anti-inflammatory macrophages M2a (CD64+ CD68+ CD206+) was increased by 1.66-fold, (Figure 7a). Exposure of M1 macrophages to EV-CPC did not impact the percentage of CD64+ CD68+ CD86+ CD80+ cells but raised by 1.64-fold the percentage of M2a cells, suggesting that even under pro-inflammatory conditions, EV-CPC favors the occurrence of anti-inflammatory M2 macrophages. Exposure of M2 macrophages to EV-CPC did not 
significantly affect the percentage of M1, M2a or M2b cells (Figure 7a). Analysis of the culture supernatants confirmed the capacity of EV to modulate cytokine levels and, more specifically, to upregulate angiogenic and anti-inflammatory markers in the treated macrophages (Figure 7b). 


\section{Discussion}

The principal findings of the present study are that EV derived from cardiovascular progenitor cells do not appear to be immunogenic and seem rather endowed with anti-inflammatory properties (Schematic representation).

The consistent observation of a discrepancy between the low engraftment rate of therapeutic cells and the maintenance of functional benefits beyond the disappearance of the grafted tissue has led the field to favor a paracrine mechanism of action whereby the transplanted cells release factors which stimulate endogenous repair pathways ${ }^{20,24,33-36}$. This mechanistic hypothesis is strengthened by the finding that the effects of transplanted cells can be recapitulated by the administration of their secretome ${ }^{5,8}$. This equivalence has been demonstrated in various and multiple preclinical models targeting different diseases ${ }^{37}$ which lends further support for the therapeutic benefits of the cellular secretome. While this secretome is comprised of multiple biologically active components, one important class which has gained increasing interest is represented by EV ${ }^{9,37-41}$. All cell types secrete EV, but not all EVs are equivalent. For example, Barile et al ${ }^{42}$ have shown that, in comparison with EV from mesenchymal stem cells, those released by cardiac stem cells have a greater therapeutic efficacy in a ischemic rat occlusion-reperfusion model. The proteomic profile from the two cell types is actually different, possibly leading to a release of factors by cardiaccommitted cells which are better tailored to heart tissue repair. Therefore, and in-line with our previous studies, we have been committed to use EV secreted from cells phenotypically close to those of the target tissue. In this case, we use iPSC derived cardiovascular progenitors. These EV were primarily characterized by their size profile, surface markers and TEM characteristics which thus provided sound evidence for their identity.

While the composition of the EV cargo reflects that of their parental cells, it can be selectively enriched in, or deprived of, some molecules present in these cells ${ }^{18}$. This is confirmed in the present study by the finding that, in contrast to CPC, the secreted EV express extremely low levels of most immune relevant molecules. Yet, they did express the ligands for NK cell activating receptors, albeit at a lower level compared to their parent cells. This expression pattern strongly suggests that EV-CPC may be more immunologically neutral towards lymphoid populations and innate lymphoid NK cells than their parent cells. This idea is supported by the fact that EV-CPC did not 
trigger allogeneic $\mathrm{T}$ cell activation either in vitro, as shown by the mixed lymphocyte reactions data. The EV-CPC are probably also unable to trigger neither T nor B cells response in vivo, since they were not able to affect the number of these adaptive cells upon their injection in immunocompetent infarcted mice. Further, EV-CPC did not trigger a humoral immune response, since their repeated delivery did not result in an increase in immunoglobulin production as compared to controls, thereby strengthening the idea that they may deviate the immune surveillance of the host. This makes them therapeutically attractive since, and in contrast to their parental allogeneic cells, their use in patients might not require immunosuppression. Of note, EV from other cell sources like antigen-presenting cells carry HLA-I and II antigens and can thus trigger T cell proliferation ${ }^{43}$. Conversely, EV from mesenchymal stem cells have been credited with immunosuppressive effects ${ }^{44}$ which we did not find to be the case for EV-CPC in our in vitro studies. Taken together, these data highlight the critical influence of the parental cell phenotype on the ultimate immune properties of their secreted EV.

The fact that EV-CPC seem endowed with anti-inflammatory properties further supports the above notion. In vivo, we consistently observed that pro-inflammatory Ly6 $\mathrm{C}^{\text {high }}$ monocytes were decreased in heart tissue in both acute MI and chronic heart failure models. This anti-inflammatory effect was more pronounced at the acute stage under the form of a concomitant decrease in neutrophils. Further evidence includes a decrease in heart and plasma cytokine levels in both acute and chronic settings and the trend for human innate myeloid monocytes/macrophages exposed to EV-CPC to shift their polarity towards an anti-inflammatory phenotype. Yet, EV-CPC were unable to reverse the pro-inflammatory M1 pattern once established concerning in vitro experiments with human cells, in contrast to exosomes from adipose-derived mesenchymal stromal cells which can reverse the M1 conversion of microglial cells subjected to oxygen and glucose deprivation ${ }^{45}$.These divergent results might be due to differences in the content of the EV payload and/or the phenotype of the target cells.

Although the present experiments focused on the immune-inflammatory responses to EV and, as such, did not include functional assessments, it is noteworthy that in a previous study from our laboratory ${ }^{6}$, EV from the same CPC source as in the present study were shown to improve post infarction contractile performance in a mouse model of chronic left ventricular dysfunction. The 
transcriptomic study of these EV had highlighted the strong expression of 16 microRNAs broadly conserved across species, among which at least half, i.e., miR-92a ${ }^{46}, \operatorname{miR}-24{ }^{47}, \mathrm{miR}-93-5 \mathrm{p}{ }^{48}, \mathrm{miR}$ 20b-5p ${ }^{49}, \operatorname{miR}-107^{50}, \mathrm{miR} 26 \mathrm{a}-5 \mathrm{p}^{51}, \mathrm{miR}-16-5 \mathrm{p}^{52}$ and miR-130b-3p ${ }^{53}$ are to some extent involved in the regulation of inflammation. It is thus plausible that the effects of the EV cargo on the mitigation of immune-inflammatory responses demonstrated in the present study participate in the previously documented EV-associated preservation of post infarction heart function. Of note, these functional benefits were observed in an immune-deficient mouse model. However, recent work in our laboratory has reproduced this therapeutic effect in an immune-competent strain (unpublished data), suggesting that the possible link between the EV-related regulation of immuneinflammatory responses and the mitigation of post infarct heart injury is independent of the immune status of the recipient animals.

The finding of decreased circulating levels of IL- $1 \alpha$ and IFN- $\gamma$ in mice, following intramyocardial injection of EV three weeks earlier, suggests that these particles might induce a sustained systemic anti-inflammatory effect not strictly localized in the treated organ. It is thus conceivable that the opposite event may happen, i.e., that intravenously delivered EV, even though they are predominantly trapped in the lungs and spleen, may exert endocrine anti-inflammatory effects on remote organs, including the heart, as reported for mesenchymal stem cells ${ }^{54}$. This could explain the therapeutic efficacy of intravenously injected EV in Duchenne ${ }^{55}$ and doxorubicin-induced cardiomyopathy ${ }^{56}$ which share in common a chronic inflammation of the myocardial tissue ${ }^{57,58}$. Should this hypothesis be validated, it would reinforce the clinical attractiveness of EV by opening the way to systemic delivery, making such a treatment simple, non-invasive, readily available and economically affordable. 
Funding: This work was supported by the Institut National de la Santé et de la Recherche Médicale; the Assistance Publique Hôpitaux de Paris; the Université Paris Descartes; the Agence Nationale de la Recherche (LabexRevive, ANR -10-LABX-73 to P.M.); the Fondation de France (FDF 00066471 to P.M. and FDF 00066471 J-S. S.), and the Fondation pour la Recherche Médicale (DEQ20160334910 to J-S. S. and P.M.).

Conflict of interests: The authors declare no competing financial interests. 


\section{References}

1. Bui AL, Horwich TB, Fonarow GC. Epidemiology and risk profile of heart failure. Nat Rev Cardiol. 2011;8:30-41.

2. Gnecchi M, Zhang Z, Ni A, Dzau VJ. Paracrine mechanisms in adult stem cell signaling and therapy. Circ Res. 2008;103:1204-1219.

3. Gallet R, Dawkins J, Valle J, Simsolo E, de Couto G, Middleton R, Tseliou E, Luthringer D, Kreke M, Smith RR, Marbán L, Ghaleh B, Marbán E. Exosomes secreted by cardiospherederived cells reduce scarring, attenuate adverse remodelling, and improve function in acute and chronic porcine myocardial infarction. Eur Heart J. 2016;Sep 27. pii: ehw240. [Epub ahead of print].

4. Lai RC, Arslan F, Lee MM, Sze NSK, Choo A, Chen TS, Salto-Tellez M, Timmers L, Lee CN, El Oakley RM, Pasterkamp G, de Kleijn DPV, Lim SK. Exosome secreted by MSC reduces myocardial ischemia/reperfusion injury. Stem Cell Res. 2010;4:214-222.

5. Kervadec A, Bellamy V, El Harane N, Arakélian L, Vanneaux V, Cacciapuoti I, Nemetalla H, Périer M-C, Toeg HD, Richart A, Lemitre M, Yin M, Loyer X, Larghero J, Hagège A, Ruel M, Boulanger CM, Silvestre J-S, Menasché P, Renault NKE. Cardiovascular progenitorderived extracellular vesicles recapitulate the beneficial effects of their parent cells in the treatment of chronic heart failure. J Heart Lung Transplant. 2016;35:795-807.

6. El Harane N, Kervadec A, Bellamy V, Pidial L, Neametalla HJ, Perier M-C, Lima Correa B, Thiébault L, Cagnard N, Duché A, Brunaud C, Lemitre M, Gauthier J, Bourdillon AT, Renault MP, Hovhannisyan Y, Paiva S, Colas AR, Agbulut O, Hagège A, Silvestre J-S, Menasché P, Renault NKE. Acellular therapeutic approach for heart failure: in vitro production of extracellular vesicles from human cardiovascular progenitors. Eur Heart J. 2018;39:18351847.

7. Timmers L, Lim SK, Hoefer IE, Arslan F, Lai RC, van Oorschot AAM, Goumans MJ, Strijder C, Sze SK, Choo A, Piek JJ, Doevendans PA, Pasterkamp G, de Kleijn DPV. Human mesenchymal stem cell-conditioned medium improves cardiac function following myocardial infarction. Stem Cell Res. 2011;6:206-214.

8. Gnecchi M, He H, Noiseux N, Liang OD, Zhang L, Morello F, Mu H, Melo LG, Pratt RE, Ingwall JS, Dzau VJ. Evidence supporting paracrine hypothesis for Akt-modified 
mesenchymal stem cell-mediated cardiac protection and functional improvement. FASEB $J$ Off Publ Fed Am Soc Exp Biol. 2006;20:661-669.

9. Ibrahim AG-E, Cheng K, Marbán E. Exosomes as critical agents of cardiac regeneration triggered by cell therapy. Stem Cell Rep. 2014;2:606-619.

10. Barile L, Lionetti V, Cervio E, Matteucci M, Gherghiceanu M, Popescu LM, Torre T, Siclari F, Moccetti T, Vassalli G. Extracellular vesicles from human cardiac progenitor cells inhibit cardiomyocyte apoptosis and improve cardiac function after myocardial infarction. Cardiovasc Res. 2014;103:530-541.

11. Zhang Y, Liu Y, Liu H, Tang WH. Exosomes: biogenesis, biologic function and clinical potential. Cell Biosci [Internet]. 2019 [cited 2019 Aug 19];9. Available from: https://www.ncbi.nlm.nih.gov/pmc/articles/PMC6377728/

12. Yuan A, Farber EL, Rapoport AL, Tejada D, Deniskin R, Akhmedov NB, Farber DB. Transfer of microRNAs by embryonic stem cell microvesicles. PloS One. 2009;4:e4722.

13. Vrijsen KR, Sluijter JPG, Schuchardt MWL, van Balkom BWM, Noort WA, Chamuleau S a. J, Doevendans P a. FM. Cardiomyocyte progenitor cell-derived exosomes stimulate migration of endothelial cells. J Cell Mol Med. 2010;14:1064-1070.

14. Sahoo S, Klychko E, Thorne T, Misener S, Schultz KM, Millay M, Ito A, Liu T, Kamide C, Agrawal H, Perlman H, Qin G, Kishore R, Losordo DW. Exosomes from human CD34(+) stem cells mediate their proangiogenic paracrine activity. Circ Res. 2011;109:724-728.

15. Chen D, Liu S, Ma H, Liang X, Ma H, Yan X, Yang B, Wei J, Liu X. Paracrine factors from adipose-mesenchymal stem cells enhance metastatic capacity through Wnt signaling pathway in a colon cancer cell co-culture model. Cancer Cell Int. 2015;15:42.

16. Cosme J, Liu PP, Gramolini AO. The cardiovascular exosome: current perspectives and potential. Proteomics. 2013;13:1654-1659.

17. Pols MS, Klumperman J. Trafficking and function of the tetraspanin CD63. Exp Cell Res. 2009;315:1584-1592.

18. Colombo M, Raposo G, Théry C. Biogenesis, secretion, and intercellular interactions of exosomes and other extracellular vesicles. Annu Rev Cell Dev Biol. 2014;30:255-289.

19. Henne WM, Buchkovich NJ, Emr SD. The ESCRT pathway. Dev Cell. 2011;21:77-91.

20. Théry C, Ostrowski M, Segura E. Membrane vesicles as conveyors of immune responses. Nat Rev Immunol. 2009;9:581-593. 
21. Lauden L, Boukouaci W, Borlado LR, López IP, Sepúlveda P, Tamouza R, Charron D, AlDaccak R. Allogenicity of human cardiac stem/progenitor cells orchestrated by programmed death ligand 1. Circ Res. 2013;112:451-464.

22. Fernandes S, Chong JJH, Paige SL, Iwata M, Torok-Storb B, Keller G, Reinecke H, Murry CE. Comparison of Human Embryonic Stem Cell-Derived Cardiomyocytes, Cardiovascular Progenitors, and Bone Marrow Mononuclear Cells for Cardiac Repair. Stem Cell Rep. 2015;5:753-762.

23. Hocine HR, Brunel S, Chen Q, Giustiniani J, Roman MJS, Ferrat YJ, Palacios I, Rosa O de la, Lombardo E, Bensussan A, Charron D, Jabrane-Ferrat N, Al-Daccak R. Extracellular Vesicles Released by Allogeneic Human Cardiac Stem/Progenitor Cells as Part of their Therapeutic Benefit. STEM CELLS Transl Med [Internet]. [cited 2019 Aug 19];0. Available from: https://stemcellsjournals.onlinelibrary.wiley.com/doi/abs/10.1002/sctm.18-0256

24. de Couto G, Gallet R, Cambier L, Jaghatspanyan E, Makkar N, Dawkins JF, Berman BP, Marbán E. Exosomal MicroRNA Transfer Into Macrophages Mediates Cellular Postconditioning. Circulation. 2017;136:200-214.

25. Davidson SM, Yellon DM. Exosomes and cardioprotection - A critical analysis. Mol Aspects Med. 2018;60:104-114.

26. Arraud N, Linares R, Tan S, Gounou C, Pasquet J-M, Mornet S, Brisson AR. Extracellular vesicles from blood plasma: determination of their morphology, size, phenotype and concentration. J Thromb Haemost JTH. 2014;12:614-627.

27. Théry C, Witwer KW, Aikawa E, Alcaraz MJ, Anderson JD, Andriantsitohaina R, Antoniou A, Arab T, Archer F, Atkin-Smith GK, Ayre DC, Bach J-M, Bachurski D, Baharvand H, Balaj L, Baldacchino S, Bauer NN, Baxter AA, Bebawy M, Beckham C, Zavec AB, Benmoussa A, Berardi AC, Bergese P, Bielska E, Blenkiron C, Bobis-Wozowicz S, Boilard E, Boireau W, Bongiovanni A, Borràs FE, Bosch S, Boulanger CM, Breakefield X, Breglio AM, Brennan MÁ, Brigstock DR, Brisson A, Broekman ML, Bromberg JF, Bryl-Górecka P, Buch S, Buck AH, Burger D, Busatto S, Buschmann D, Bussolati B, Buzás EI, Byrd JB, Camussi G, Carter DR, Caruso S, Chamley LW, Chang Y-T, Chen C, Chen S, Cheng L, Chin AR, Clayton A, Clerici SP, Cocks A, Cocucci E, Coffey RJ, Cordeiro-da-Silva A, Couch Y, Coumans FA, Coyle B, Crescitelli R, Criado MF, D’Souza-Schorey C, Das S, Chaudhuri AD, Candia P de, Junior EFDS, Wever OD, Portillo HA del, Demaret T, Deville S, Devitt A, Dhondt B, Vizio 
DD, Dieterich LC, Dolo V, Rubio APD, Dominici M, Dourado MR, Driedonks TA, Duarte FV, Duncan HM, Eichenberger RM, Ekström K, Andaloussi SE, Elie-Caille C, Erdbrügger U, Falcón-Pérez JM, Fatima F, Fish JE, Flores-Bellver M, et al. Minimal information for studies of extracellular vesicles 2018 (MISEV2018): a position statement of the International Society for Extracellular Vesicles and update of the MISEV2014 guidelines. $J$ Extracell Vesicles. 2018;7:1535750.

28. Gunasekaran M, Sharma M, Hachem R, Bremner R, Smith MA, Mohanakumar T. Circulating Exosomes with Distinct Properties during Chronic Lung Allograft Rejection. J Immunol Baltim Md 1950. 2018;200:2535-2541.

29. Zlatanova I, Pinto C, Bonnin P, Mathieu JRR, Bakker W, Vilar J, Lemitre M, Voehringer D, Vaulont S, Peyssonnaux C, Silvestre J-S. Iron Regulator Hepcidin Impairs MacrophageDependent Cardiac Repair After Injury. Circulation. 2019;139:1530-1547.

30. Prabhu SD, Frangogiannis NG. The Biological Basis for Cardiac Repair After Myocardial Infarction: From Inflammation to Fibrosis. Circ Res. 2016;119:91-112.

31. Cochain C, Auvynet C, Poupel L, Vilar J, Dumeau E, Richart A, Récalde A, Zouggari Y, Yin KYHW, Bruneval P, Renault G, Marchiol C, Bonnin P, Lévy B, Bonecchi R, Locati M, Combadière C, Silvestre J-S. The chemokine decoy receptor D6 prevents excessive inflammation and adverse ventricular remodeling after myocardial infarction. Arterioscler Thromb Vasc Biol. 2012;32:2206-2213.

32. Chandra R, Villanueva E, Feketova E, Machiedo GW, Haskó G, Deitch EA, Spolarics Z. Endotoxemia down-regulates bone marrow lymphopoiesis but stimulates myelopoiesis: the effect of G6PD deficiency. J Leukoc Biol. 2008;83:1541-1550.

33. Théry C, Zitvogel L, Amigorena S. Exosomes: composition, biogenesis and function. Nat Rev Immunol. 2002;2:569-579.

34. EL Andaloussi S, Mäger I, Breakefield XO, Wood MJA. Extracellular vesicles: biology and emerging therapeutic opportunities. Nat Rev Drug Discov. 2013;12:347-357.

35. Camussi G, Deregibus MC, Bruno S, Cantaluppi V, Biancone L. Exosomes/microvesicles as a mechanism of cell-to-cell communication. Kidney Int. 2010;78:838-848.

36. Camussi G, Deregibus M-C, Bruno S, Grange C, Fonsato V, Tetta C. Exosome/microvesiclemediated epigenetic reprogramming of cells. Am J Cancer Res. 2011;1:98-110. 
37. Lener T, Gioma M, Aigner L, Börger V, Buzas E, Camussi G, Chaput N, Chatterjee D, Court FA, Portillo HA del, O’Driscoll L, Fais S, Falcon-Perez JM, Felderhoff-Mueser U, Fraile L, Gho YS, Görgens A, Gupta RC, Hendrix A, Hermann DM, Hill AF, Hochberg F, Horn PA, Kleijn D de, Kordelas L, Kramer BW, Krämer-Albers E-M, Laner-Plamberger S, Laitinen S, Leonardi T, Lorenowicz MJ, Lim SK, Lötvall J, Maguire CA, Marcilla A, Nazarenko I, Ochiya T, Patel T, Pedersen S, Pocsfalvi G, Pluchino S, Quesenberry P, Reischl IG, Rivera FJ, Sanzenbacher R, Schallmoser K, Slaper-Cortenbach I, Strunk D, Tonn T, Vader P, Balkom BWM van, Wauben M, Andaloussi SE, Théry C, Rohde E, Giebel B. Applying extracellular vesicles based therapeutics in clinical trials - an ISEV position paper. $J$ Extracell Vesicles [Internet]. 2015 [cited 2016 Oct 6];4. Available from: http://www.journalofextracellularvesicles.net/index.php/jev/article/view/30087

38. Xin H, Li Y, Cui Y, Yang JJ, Zhang ZG, Chopp M. Systemic administration of exosomes released from mesenchymal stromal cells promote functional recovery and neurovascular plasticity after stroke in rats. J Cereb Blood Flow Metab. 2013;33:1711-1715.

39. Kamata S, Miyagawa S, Fukushima S, Nakatani S, Kawamoto A, Saito A, Harada A, Shimizu T, Daimon T, Okano T, Asahara T, Sawa Y. Improvement of cardiac stem cell sheet therapy for chronic ischemic injury by adding endothelial progenitor cell transplantation: analysis of layer-specific regional cardiac function. Cell Transplant. 2014;23:1305-1319.

40. Vlassov AV, Magdaleno S, Setterquist R, Conrad R. Exosomes: current knowledge of their composition, biological functions, and diagnostic and therapeutic potentials. Biochim Biophys Acta. 2012;1820:940-948.

41. Menasché P. Stem cell-derived exosomes and the failing heart: Small cause, big effect. $J$ Thorac Cardiovasc Surg. 2018;156:1089-1092.

42. Barile L, Cervio E, Lionetti V, Milano G, Ciullo A, Biemmi V, Bolis S, Altomare C, Matteucci M, Di Silvestre D, Brambilla F, Fertig TE, Torre T, Demertzis S, Mauri P, Moccetti T, Vassalli G. Cardioprotection by cardiac progenitor cell-secreted exosomes: role of pregnancy-associated plasma protein-A. Cardiovasc Res. 2018;114:992-1005.

43. Robbins PD, Morelli AE. Regulation of immune responses by extracellular vesicles. Nat Rev Immunol. 2014;14:195-208. 
44. Börger V, Bremer M, Ferrer-Tur R, Gockeln L, Stambouli O, Becic A, Giebel B. Mesenchymal Stem/Stromal Cell-Derived Extracellular Vesicles and Their Potential as Novel Immunomodulatory Therapeutic Agents. Int J Mol Sci. 2017;18.

45. Jiang M, Wang H, Jin M, Yang X, Ji H, Jiang Y, Zhang H, Wu F, Wu G, Lai X, Cai L, Hu R, $\mathrm{Xu} \mathrm{L,} \mathrm{Li} \mathrm{L.} \mathrm{Exosomes} \mathrm{from} \mathrm{MiR-30d-5p-ADSCs} \mathrm{Reverse} \mathrm{Acute} \mathrm{Ischemic} \mathrm{Stroke-Induced,}$ Autophagy-Mediated Brain Injury by Promoting M2 Microglial/Macrophage Polarization. Cell Physiol Biochem Int J Exp Cell Physiol Biochem Pharmacol. 2018;47:864-878.

46. Lai L, Song Y, Liu Y, Chen Q, Han Q, Chen W, Pan T, Zhang Y, Cao X, Wang Q. MicroRNA92a negatively regulates Toll-like receptor (TLR)-triggered inflammatory response in macrophages by targeting MKK4 kinase. J Biol Chem. 2013;288:7956-7967.

47. Tahamtan A, Teymoori-Rad M, Nakstad B, Salimi V. Anti-Inflammatory MicroRNAs and Their Potential for Inflammatory Diseases Treatment. Front Immunol. 2018;9:1377.

48. Liu J, Jiang M, Deng S, Lu J, Huang H, Zhang Y, Gong P, Shen X, Ruan H, Jin M, Wang H. miR-93-5p-Containing Exosomes Treatment Attenuates Acute Myocardial InfarctionInduced Myocardial Damage. Mol Ther Nucleic Acids. 2018;11:103-115.

49. You H, Zhang L, Chen Z, Liu W, Wang H, He H. MiR-20b-5p relieves neuropathic pain by targeting Akt3 in a chronic constriction injury rat model. Synap N Y N. 2019;73:e22125.

50. Gao Z-F, Ji X-L, Gu J, Wang X-Y, Ding L, Zhang H. microRNA-107 protects against inflammation and endoplasmic reticulum stress of vascular endothelial cells via KRT1dependent Notch signaling pathway in a mouse model of coronary atherosclerosis. $J$ Cell Physiol. 2019;234:12029-12041.

51. Kong B, Qin Z, Ye Z, Yang X, Li L, Su Q. microRNA-26a-5p affects myocardial injury induced by coronary microembolization by modulating HMGA1. J Cell Biochem. 2019;120:10756-10766.

52. Lei J, Fu Y, Zhuang Y, Zhang K, Lu D. LncRNA SNHG1 alleviates IL-1 $\beta$-induced osteoarthritis by inhibiting miR-16-5p-mediated p38 MAPK and NF- $\kappa$ B signaling pathways. Biosci Rep. 2019;39.

53. Wang P, Zhang X, Li F, Yuan K, Li M, Zhang J, Li B, Liang W. MiR-130b attenuates vascular inflammation via negatively regulating tumor progression locus 2 (Tpl2) expression. Int Immunopharmacol. 2017;51:9-16. 
54. Luger D, Lipinski MJ, Westman PC, Glover DK, Dimastromatteo J, Frias JC, Albelda MT, Sikora S, Kharazi A, Vertelov G, Waksman R, Epstein SE. Intravenously Delivered Mesenchymal Stem Cells: Systemic Anti-Inflammatory Effects Improve Left Ventricular Dysfunction in Acute Myocardial Infarction and Ischemic Cardiomyopathy. Circ Res. 2017;120:1598-1613.

55. Rogers RG, Fournier M, Sanchez L, Ibrahim AG, Aminzadeh MA, Lewis MI, Marbán E. Disease-modifying bioactivity of intravenous cardiosphere-derived cells and exosomes in mdx mice. JCI Insight. 2019;4.

56. Milano G, Biemmi V, Lazzarini E, Balbi C, Ciullo A, Bolis S, Ameri P, Di Silvestre D, Mauri P, Barile L, Vassalli G. Intravenous administration of cardiac progenitor cell-derived exosomes protects against doxorubicin/trastuzumab-induced cardiac toxicity. Cardiovasc Res. 2019;

57. Mavrogeni S, Papavasiliou A, Spargias K, Constandoulakis P, Papadopoulos G, Karanasios E, Georgakopoulos D, Kolovou G, Demerouti E, Polymeros S, Kaklamanis L, Magoutas A, Papadopoulou E, Markussis V, Cokkinos DV. Myocardial inflammation in Duchenne Muscular Dystrophy as a precipitating factor for heart failure: a prospective study. BMC Neurol. 2010;10:33.

58. Sun X, Shan A, Wei Z, Xu B. Intravenous mesenchymal stem cell-derived exosomes ameliorate myocardial inflammation in the dilated cardiomyopathy. Biochem Biophys Res Commun. 2018;503:2611-2618. 


\section{Figure legends}

\section{Figure 1: Surface marker profile of CPC and EV-CPC:}

a \& b) Representative flow cytometry histograms for the fluorescence intensity of surface markers on CPC (a) and EV-CPC (b). The percentage of positive cells (\%) and geometric mean fluorescence intensity (MFI) are indicated. mAb (monoclonal antibody). c) Main surface marker profile of EVCPC, as identified by a cocktail of 39 fluorescently-labeled bead populations, each coated with a specific antibody binding the respective EV surface epitope. These data were derived from 4 independent preparations of EV. Data are presented as box-and-whisker plots, with the midline representing the median and the whiskers representing maximum and minimum values. d) The upper and middle panels present representative cryo-TEM images of CD81+ and CD81- EV embedded in a thin film of frozen buffer. The lipid bilayer is clearly resolved (arrow in the upper panel). The lower panel presents the size distribution of CD81+ and CD81- EVs, determined over a total of $350 \mathrm{EV}$. The median sizes are $175 \mathrm{nM}$ and $265 \mathrm{nM}$ for CD81+ and CD81- EV, respectively. CPC: iPS-derived cardiovascular progenitor cells; EV: Extracellular vesicles from iPS-derived cardiovascular progenitor cells.

\section{Figure 2: Effects of CPC and EV-CPC on allogeneic T-cell immune response.}

a) CFSE-labeled peripheral blood mononuclear cells (PBMC) were cultured alone (negative control), with human leukocyte antigen-mismatched mitomycin C-treated PBMC (Allo PBMC from 2 different donors, positive control), with mitomycin C-treated CPC at different CPC:PBMC ratios (CPC1: 1:10; $\mathrm{CPC} 2: 1: 5)$, or with $\mathrm{EV}-\mathrm{CPC}$ at different doses (EV1: 5.5x10 ${ }^{8} ; \mathrm{EV} 2: 5.5 \times 10^{9}$ and EV3: $1.7 \times 10^{10}$ particles). Proliferation levels of $\mathrm{CD}^{+}$and $\mathrm{CD} 8^{+} \mathrm{T}$ cells were determined by loss of CFSE labelling.

b) CFSE-labeled human leukocyte antigen-mismatched PBMC were activated with phytohemagglutinin ((PHA)-positive control), alone (negative control), in the presence of mitomycin C-treated CPC at different CPC:PBMC ratios (CPC1: 1:10; CPC2: 1:5), or with EVCPC at different doses (EV1: $5.5 \times 10^{8}$; EV2: $5.5 \times 10^{9}$ and EV3: $1.7 \times 10^{10}$ particles). Proliferation levels of $\mathrm{CD}^{+}$and $\mathrm{CD}^{+} \mathrm{T}$ cells were determined by loss of CFSE labelling. The results are given as mean \pm SD from 3 independent experiments performed in duplicate or triplicate. Wilcoxon signed rank test was used and a $p$-value $<0.05$ was considered statistically significant ${ }^{* *} p \leq 0.01$; $* * * p \leq 0.001$. Abbreviations as in Figure 1 . 


\section{Figure 3: Effects of CPC and EV-CPC on NK cell degranulation.}

a) Scatter plot of flow cytometry analysis showing the percentages of CD107a-positive cells in CD56+ IL-15-activated NK cells after overnight incubation with target cells: K562 (positive control), CPC or EV-CPC (EV1: 5.5 $\times 10^{8}$; EV2: $5.5 \times 10^{9}$ and EV3: $1.7 \times 10^{10}$ particles) at a $1: 1$ effector:target cell ratio.

b) Histogram presenting percentages of CD107a positive cells (mean \pm SD) from 3 independent experiments performed in triplicate. The results are given as mean \pm SD. Wilcoxon signed rank test was used, a $p$-value $<0.05$ was considered statistically significant. $* * * p \leq 0.001$. Abbreviations as in Figure 1.

\section{Figure 4: Humoral and cellular responses of vaccinated mice with PBS or EV-CPC.}

a) Immunoglobulin isotype detection in plasma of vaccinated mice at days 10, 20, 30 and 37.

b) Spot counts of interferon-gamma (IFN- $\gamma$ ) detection secreted by splenocytes of each vaccinated mouse (technical triplicates), $\mathrm{n}=6$ per group. PBS: Phosphate-Buffered saline; other abbreviations as in Figure 1.

Figure 5: Inflammatory cell numbers in heart tissue and cytokine blood levels in the chronic heart failure model.

a) Heart tissue levels of immune cells: Three weeks after MI, mice were untreated $(n=8-13)$ or injected with PBS (n=6-8), EV (n=7), CPC (n=6) or LPS $(n=4)$. Three days after injection, the left ventricle was removed and analysed by FACS for the assessment of immune cells.

b) Circulating blood cytokine measurements, assessed by FACS using a Luminex ${ }^{\circledR}$ based-bead immuno assay. Untreated (n=3-5), PBS $(n=4-6)$, EV $(n=5-6)$, CPC $(n=3-5)$ or LPS $(n=3)$. The results are given as mean $\pm \mathrm{SD}$. Wilcoxon signed rank test was used, a $p$-value $<0.05$ was considered statistically significant. ${ }^{*} p \leq 0.05 ; * * \leq 0.01$. Abbreviations as in Figure 4.

Figure 6: Inflammatory cell numbers and cytokine levels in heart tissue in the acute myocardial infarction model. 
a) Heart tissue levels of immune cells: Two days after MI, mice were injected with PBS (n=6) or EV $(n=6)$. Three days after injection, the left ventricle was removed and analysed by FACS for the assessment of immune cells.

b) Cardiac cytokine levels, as assessed by FACS using a Luminex® based-bead immuno-assay; PBS $(n=5-6)$ or EV $(n=6-7)$. The results are given as mean \pm SD. Wilcoxon signed rank test was used, a $p$-value $<0.05$ was considered statistically significant. ${ }^{*} p \leq 0.05$. Abbreviations as in Figure 4.

\section{Figure 7: Effects of EV-CPC on the expression of macrophage surface markers and cytokine expression profile.}

a) Percentage of cell expressing specific surface markers in human macrophages (CD64+ and CD68+, $n=3$ or 4 different patients). The results are given as mean \pm SEM. Mann-Whitney Test was used to compare two groups and a p-value $<0.05$ was considered statistically significant.

b) Supernatants of macrophage cell culture at day 9 were analyzed by FACS using a Luminex beadbased immunoassay. Values have been normalized in reference to the untreated population in each case. Data were obtained from 4 different patients. The results are given as mean \pm SD. MannWhitney Test was used to compare two groups and a p-value $<0.05$ was considered statistically significant; $* \mathrm{p} \leq 0.05$.

M0: Undifferentiated macrophages; M1: Pro-inflammatory macrophages; M2: Anti-inflammatory macrophages; EV: Extracellular vesicles from iPS cell-derived cardiovascular progenitor cells.

Schematic representation: EV and cardiac inflammatory reaction. Extracellular vesicles (EV) obtained from iPS cell-derived cardiovascular progenitor cells (CPC) do not trigger an immune response either in in vitro human allogeneic settings or in immunocompetent experimental models. Of note, EV harbor an unchallenged capacity to fine-tune the response of monocyte/macrophages towards resolution of inflammation bolstering their therapeutic potential. 